\title{
Economical and Efficient Protection for Blast Furnace Hearth
}

\author{
Yong DENG, ${ }^{1,2)}$ Jian-liang ZHANG ${ }^{1,2)}$ and Ke-xin $\mathrm{JIAO}^{1,2) *}$ \\ 1) School of Metallurgical and Ecological Engineering, University of Science and Technology Beijing, Beijing, 100083 China. \\ 2) State Key Laboratory of Advanced Metallurgy, University of Science and Technology Beijing, Beijing, 100083 China.
}

(Received on January 4, 2018; accepted on April 2, 2018; J-STAGE Advance published date: June 9, 2018)

\begin{abstract}
In order to clarify the erosion mechanism of carbon brick and realize the economical and efficient protection for blast furnace hearth at the end of the service. The damaged carbon bricks were sampled from a commercial blast furnace, the microstructure of the damaged carbon bricks was analyzed through SEM and EDS. The carbon undersaturation degrees of molten iron for different volume blast furnace were calculated, the dissolution and the penetration were considered as the reasons for the erosion of carbon brick. A model of economical and efficient protection for hearth was established based on various factors, the economy of protection raw material and the protection effect can be evaluated through the model. The model guides the selection of the economical protection raw material according to the evaluation, the reasonable operation can be obtained according to the calculation of the fettling rate.
\end{abstract}

KEY WORDS: blast furnace; economical and efficient protection; carbon undersaturation degree; economic evaluation; fettling rate.

\section{Introduction}

The accidents of blast furnace(BF) hearth were reported frequently. ${ }^{1,2)}$ The burn out of hearth occurred from small BF $\left(100 \mathrm{~m}^{3}\right)$ to large BF $\left(4747 \mathrm{~m}^{3}\right)$, hearth had always been the limiting area for long campaign life of BF. ${ }^{3)}$ However, the erosion mechanism of carbon brick was not clear although many dissection investigations were carried out in the past. ${ }^{4,5}$ Raw materials containing titania charged in $\mathrm{BF}$ is the universal measure to prolong the service life of hearth. The injection of titania powder from tuyere and the application of taphole clay containing titania are considered as effective methods, while, the addition of ore containing titania from BF top is announced more convenient. ${ }^{6-9)}$

Titania content, total iron grade, basicity and price change with the variety of ore. It is the concern for operators to choose the economical ore containing titania for protection. ${ }^{10-12)}$ The effect of titania content on metallurgical properties of the ore was investigated by many papers, ${ }^{13,14)}$ the evaluation of the economy only based on price was concluded to be one-sided, few people synthetically evaluate the economy of the ore containing titania based on the price, the flux amount, the iron production and the slag amount. ${ }^{15)}$ In addition, the evaluation index of the protection effect is lacking, the stability of the protection effect can't be guaranteed due to the change of operation, the time to increase titanium load becomes the key for operators. ${ }^{16,17)}$

In the current study, the reasons for the erosion of carbon brick were analyzed, a model of economical and efficient protection for hearth was established based on various

\footnotetext{
* Corresponding author: E-mail: jiaokexin_ustb@126.com DOI: http://dx.doi.org/10.2355/isijinternational.ISIJINT-2018-005
}

factors, the evaluation index of the protection effect was obtained according to the calculation of the fettling rate.

\section{Experimental}

\subsection{The Erosion Morphology of Carbon Brick}

The studied BF $\left(1780 \mathrm{~m}^{3}\right)$ was blown in on December 30, 2007 and shut down on August 3, 2015. The hearth sidewall was lined with carbon bricks and the ceramic cup, the hearth was dissected after blow-out. The damaged carbon bricks were sampled from the hot face of the hearth, the circumferential and vertical positions of the damaged carbon bricks were shown in Figs. 1(a) and 1(b).

The SEM and EDS results of sample 1 are presented in Fig. 2, the hot face of the damaged carbon brick is presented in Fig. 2(a). When molten iron is in contact with the carbon brick directly, the penetration of molten iron occurred through the micropore of carbon brick. The molten iron penetrated into the pores of carbon brick, after the pores were enlarged, the molten iron in the pores was joined together Fig. 2(b). Fine cracks formed after the penetration, the embrittlement of carbon brick appeared due to the strength decreased, carbon brick particles will fall off from the matrix.

Microstructures of sample 2 analyzed through SEM and EDS are shown in Fig. 3, the surface scanning of interface indicates the carbon brick had been surrounded by molten iron, the high carbon content in molten iron near the interface illustrates that the carburization occurred which demonstrate the erosion of carbon brick was caused by the dissolution of molten iron. 

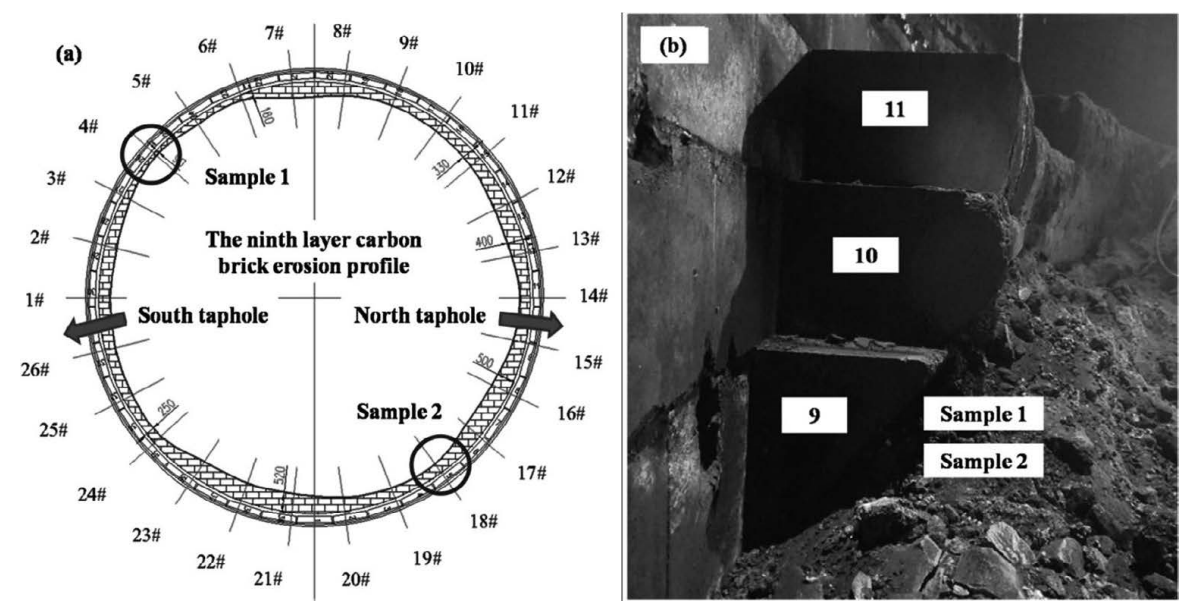

Fig. 1. The circumferential and vertical positions of the samples.
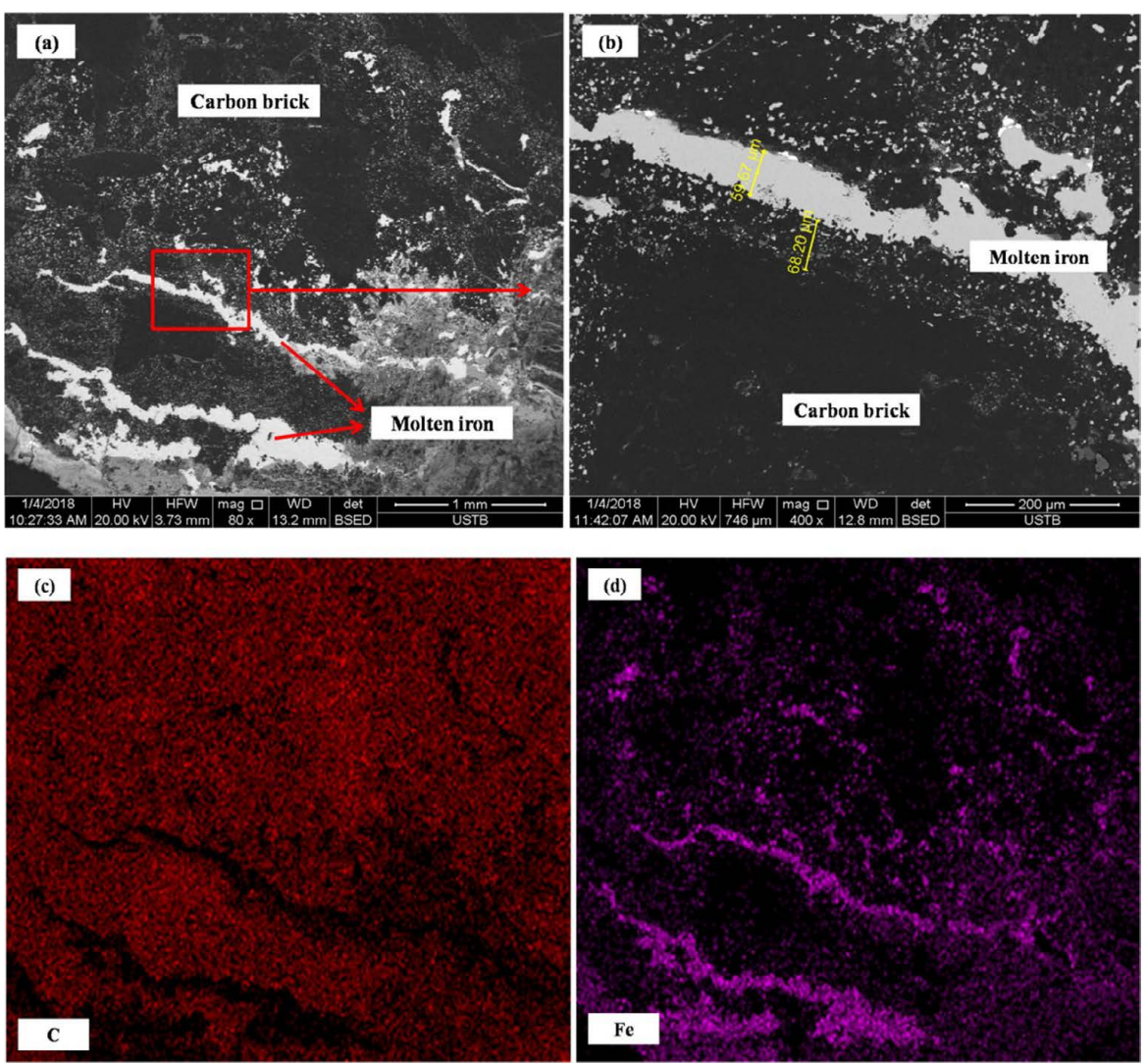

Fig. 2. Microstructure of sample 1. (Online version in color.)

\subsection{The Carbon Undersaturation Degree of Molten Iron in Hearth}

Carbon has a great influence on the melting point of molten iron, the precipitation of graphite, the viscosity of molten iron and the erosion carbon brick. ${ }^{18,19)}$ The carburizing reaction begins with the appearance of metal iron, it is known from iron-carbon phase diagram that the saturated carbon content in molten iron is related to the temperature, the amount of carbon to reach the saturation of molten iron is high owing to the molten iron temperature of large $\mathrm{BF}$ is high.

In addition to the temperature, the saturated carbon content in molten iron is also related to the composition of molten iron, it can be calculated by the following equation: ${ }^{20)}$

$$
\begin{aligned}
& {[C]_{\text {sat }}=1.34+2.54 \times 10^{-3}(T-273)-0.35[\% \mathrm{P}]} \\
& +0.17[\% \mathrm{Ti}]-0.54[\% \mathrm{~S}]+0.04[\% \mathrm{Mn}]-0.30[\% \mathrm{Si}]
\end{aligned}
$$

where $[C]_{\text {sat }}$ is the saturated carbon content in molten iron, $\%$; $\mathrm{T}$ is the temperature of molten iron, $\mathrm{K} ;[\% i]$ is the element content of molten iron.

The calculation results of different volume BF are presented in Table 1, the saturated carbon content of different volume $\mathrm{BF}$ is about $5 \%$, the content of the carbon is undersaturated compared with the actual carbon content in molten iron. The actual molten iron in hearth had been put into a high temperature tube furnace, and heated to $1773 \mathrm{~K}$ under argon protection, the carbon content increased with the time.

Both theoretical calculation and experiment show that the 

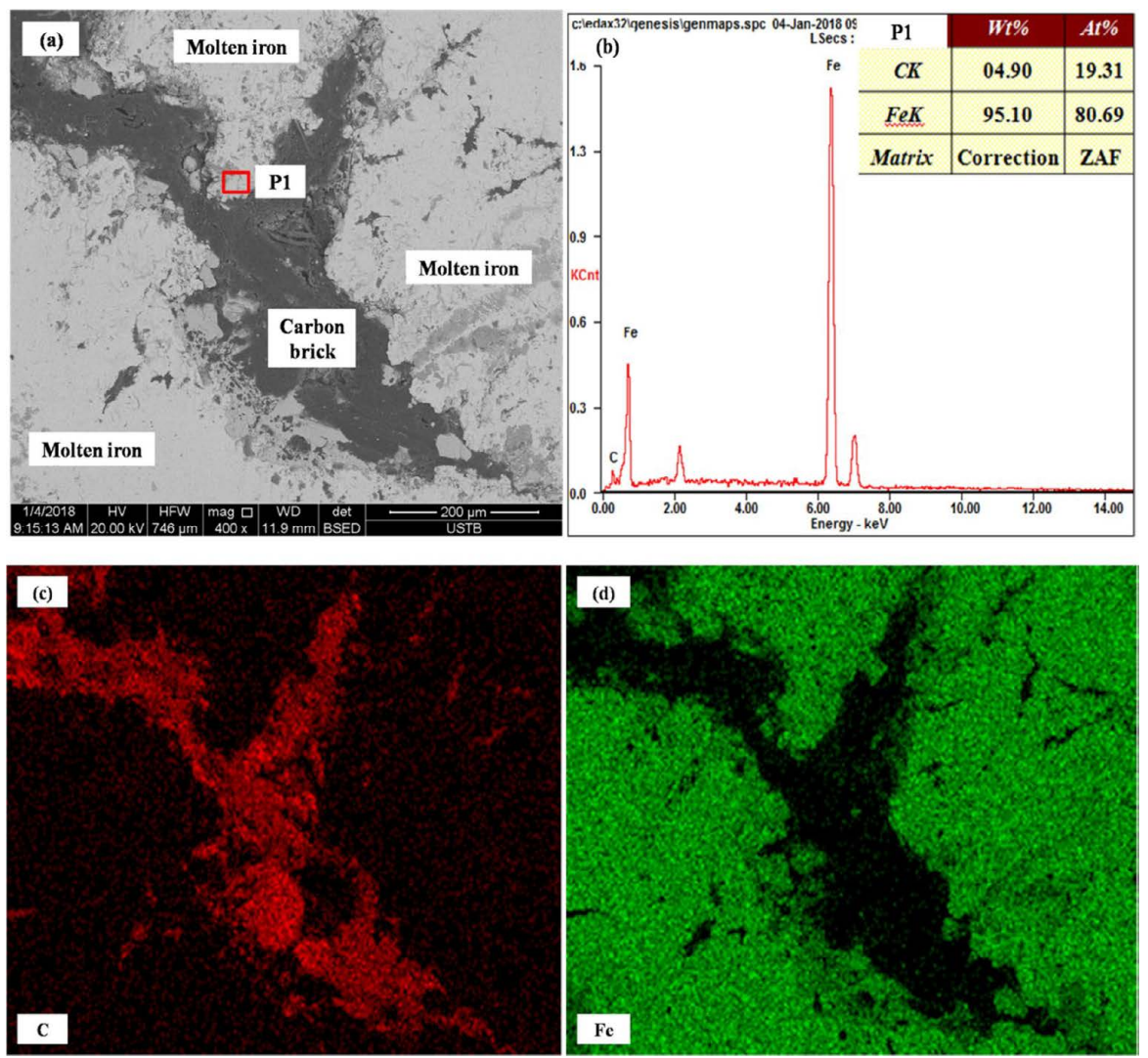

Fig. 3. Microstructure of sample 2. (Online version in color.)

Table 1. The carbon undersaturation degrees of different volume BF.

\begin{tabular}{rrrrrrrrrr}
\hline $\mathrm{V}, \mathrm{m}^{3}$ & $\mathrm{~T},{ }^{\circ} \mathrm{C}$ & $\mathrm{C}, \%$ & $\mathrm{Si}, \%$ & $\mathrm{Mn}, \%$ & $\mathrm{P}, \%$ & $\mathrm{~S}, \%$ & $\mathrm{Ti}, \%$ & $\mathrm{C}_{\mathrm{sat}}, \%$ & $\delta, \%$ \\
\hline 450 & 1479 & 4.57 & 0.51 & 0.29 & 0.105 & 0.026 & 0.051 & 4.91 & 6.92 \\
1050 & 1483 & 4.68 & 0.32 & 0.32 & 0.100 & 0.057 & 0.102 & 4.98 & 6.02 \\
1780 & 1490 & 4.84 & 0.32 & 0.28 & 0.099 & 0.032 & 0.034 & 4.99 & 3.01 \\
2600 & 1505 & 4.87 & 0.46 & 0.15 & 0.093 & 0.030 & 0.118 & 5.00 & 2.60 \\
3200 & 1509 & 4.83 & 0.35 & 0.28 & 0.092 & 0.027 & 0.042 & 5.04 & 4.17 \\
4747 & 1508 & 4.89 & 0.44 & 0.17 & 0.081 & 0.026 & 0.045 & 5.01 & 2.40
\end{tabular}

carbon content is undersaturated in hearth, the carbon undersaturation degrees of different volume BF can be calculated:

$$
\delta=\frac{[C]_{\text {sat }}-[C]_{\text {act }}}{[C]_{\text {sat }}} \times 100 \%
$$

where $\delta$ is the carbon undersaturation degree, $\% ;[C]_{\text {sat }}$ is the saturated carbon content in molten iron, $\%$; $[C]_{\text {act }}$ is the actual carbon content in molten iron, $\%$.

Table 1 presents that carbon content is undersaturated in hearth for all BFs, while the carbon undersaturation degree is related to the volume of $\mathrm{BF}$, the actual carbon content of molten iron increases with the increase of BF volume (Fig. 4), therefore, the carbon undersaturation degree of large $\mathrm{BF}$ is lower which may be the reason of long service life for large $\mathrm{BF}$.

\subsection{The Erosion Process of Carbon Brick and the For- mation of Titanium Bearing Protective Layer}

The erosion of carbon brick can be divided into four processes (Fig. 5): 1) Molten iron contacts the carbon brick

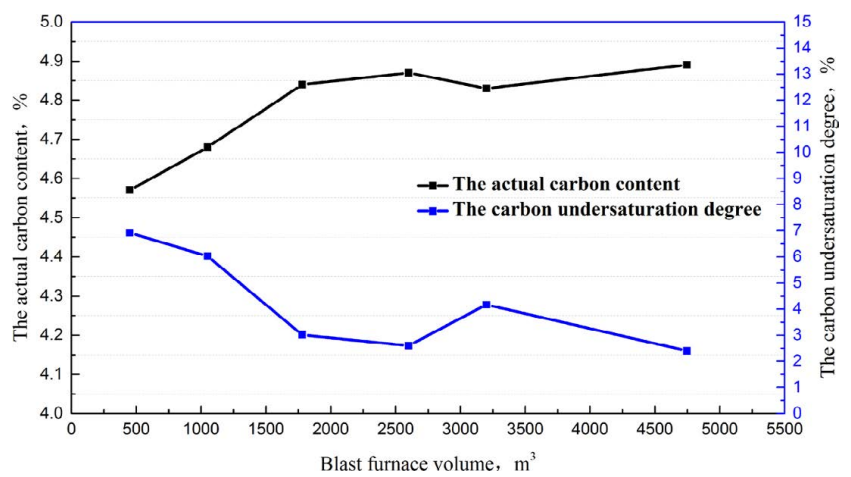

Fig. 4. The carbon undersaturation degrees of different volume BF. (Online version in color.)

directly; 2) The penetration of molten iron occurs through the micropore of carbon brick; 3) The embrittlement of carbon brick appears due to the strength decreases, carbon brick particles will fall off from the matrix; 4) The dissolution of carbon brick occurs owing to the carbon content of molten iron is undersaturated in hearth. The four processes constitute a cycle which causes the erosion of carbon brick gradually.

The protective layer should be established to insulate the molten iron and the carbon brick. After the addition of materials containing titania, the titania is reduced to titanium and dissolved into the molten iron. As the operational condition of the BF change, molten iron containing titanium will migrate to the low temperature region of the hearth. It can crystallize in the form of $\mathrm{TiC}$ and $\mathrm{TiN}$ or $\mathrm{Ti}(\mathrm{C}, \mathrm{N})$ solid solution on the hot face of the damaged carbon brick when titanium in molten iron is saturated, these high melting point materials gradually form a protective layer to delay the erosion of carbon brick. 


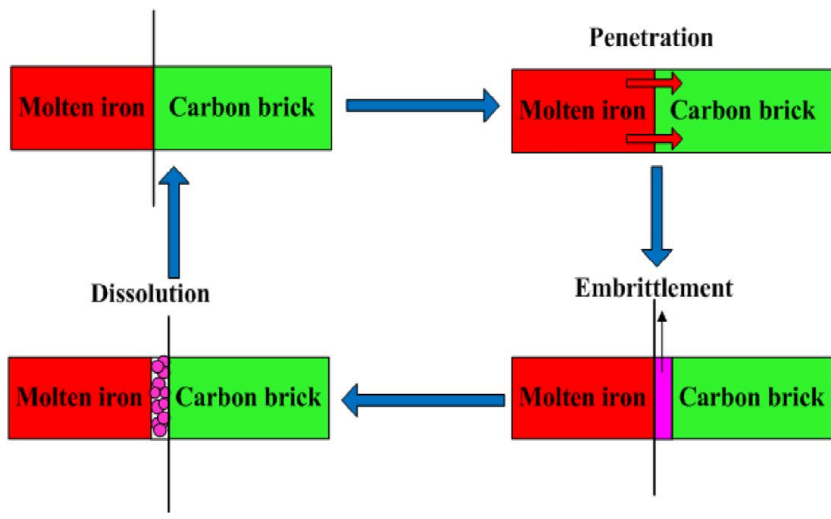

Fig. 5. Schematic diagram of the erosion process. (Online version in color.)

\section{The Model of Economical and Efficient Protection for Hearth}

\subsection{Economic Evaluation of Raw Material for Protec- tion}

The economic evaluation was established based on the titanium content of molten iron, the distribution ratio of titanium, the composition of raw material, the price of raw material and the operation of $\mathrm{BF}$. The calculation process is summarized in Fig. 6

Firstly, the lower limit of the effective titanium content in molten iron is obtained according to the thermocouple temperature during protection. The maximum titanium distribution ratio (the situation of titanium from slag to molten iron at most) is taken to calculate the titania content in slag. Thus, the economic titanium load can be calculated based on titanium balance.

The total cost consists of four parts: cost of raw material for protection, cost of flux consumption, saving the cost of molten iron and cost of coke consumption. The basic materials remains unchanged, calculate the cost of raw material for protection.

Cost of raw material for protection : $P_{1}=m_{1} \times p_{1} \ldots$

where $P_{1}$ is cost of raw material for protection, $\mathrm{RMB} / \mathrm{t} ; m_{1}$ is the raw material mass for protection, $\mathrm{kg} / \mathrm{t} ; p_{1}$ is the raw material price for protection, $\mathrm{RMB} / \mathrm{kg}$.

The $\mathrm{CaO}$ mass change after adding the titanium resources can be calculated on the premise of keeping the basicity of the slag constant, so the cost of flux consumption can be obtained.

$$
\begin{aligned}
& \text { Cost of flux consumption : } \frac{m_{P-\mathrm{CaO}}+\Delta m_{\mathrm{CaO}}}{m_{P-\mathrm{SiO}_{2}}}=R \ldots \\
& \qquad P_{2}=\Delta m_{\mathrm{CaO}} \times p_{2} \ldots \ldots \ldots \ldots \ldots \ldots \ldots \ldots \ldots \ldots \ldots \ldots \ldots \ldots \ldots \ldots \ldots
\end{aligned}
$$

where $R$ is the basicity of slag; $m_{P-C a O}$ is the $\mathrm{CaO}$ mass of raw materials for protection, $\mathrm{kg} ; \Delta m_{\mathrm{CaO}}$ is the $\mathrm{CaO}$ mass change after adding the titanium resources, $\mathrm{kg} / \mathrm{t} ; m_{P-S_{2} O_{2}}$ is the $\mathrm{SiO}_{2}$ mass of raw materials for protection, $\mathrm{kg} ; P_{2}$ is the cost of flux consumption, $\mathrm{RMB} / \mathrm{t} ; p_{2}$ is the $\mathrm{CaO}$ price, $\mathrm{RMB} / \mathrm{kg}$.

The extra molten iron mass can be calculated through the grade of raw materials for protection as raw materials for protection contain iron, therefore, the cost of saving can be

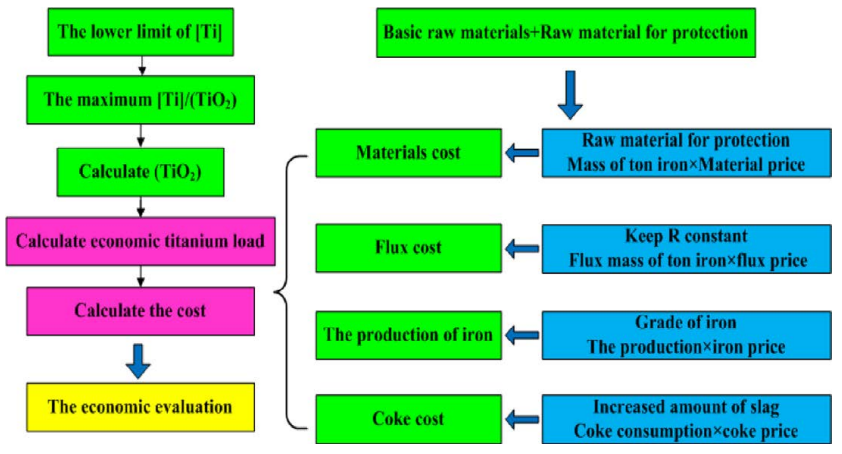

Fig. 6. Schematic diagram of the economic evaluation. (Online version in color.)

obtained.

Saving the cost of molten iron : $m_{1} \times \mathrm{TFe} / 100=m_{\text {iron }} \ldots(6)$

$$
P_{3}=m_{\text {iron }} \times p_{3}
$$

where $\mathrm{TFe}$ is the grade of iron, $\% ; m_{\text {iron }}$ is the extra molten iron mass, $\mathrm{kg} / \mathrm{t} ; P_{3}$ is cost of saving, $\mathrm{RMB} / \mathrm{t} ; p_{3}$ is the price of molten iron, $\mathrm{RMB} / \mathrm{kg}$.

The impurities brought by the raw materials for protection will increase the amount of slag and consume heat, moreover, the desulphurization is a heat consuming reaction while the heat consumed is provided by coke. The consumption of heat can be calculated based on the mass and composition of the raw materials for protection, therefore, the coke cost can be obtained.

$$
\text { Coke cost : } Q=\sum C_{i} m_{i} \Delta T
$$

$$
P_{4}=m_{\text {Coke }} \times p_{4}
$$

where $Q$ is the consumption of heat, $\mathrm{kJ} ; C_{i}$ is the heat capacity, $\mathrm{kJ} /(\mathrm{kg} \cdot \mathrm{K}) ; m_{i}$ is the impurity mass, $\mathrm{kg} ; \Delta T$ is the temperature difference between slag and room, $\mathrm{K} ; P_{4}$ is the cost of coke, $\mathrm{RMB} / \mathrm{t} ; m_{\text {Coke }}$ is the mass of coke, $\mathrm{kg} ; p_{4}$ is the price of coke, $\mathrm{RMB} / \mathrm{t}$.

$$
P=P_{1}+P_{2}+P_{3}+P_{4}
$$

The total cost $P$ can be used to compare the economy of the raw materials for protection.

\subsection{The Protection Effect Evaluation Based on the Fet- tling Rate}

The stability of the protection effect can't be guaranteed due to the change of operation, the time to increase titanium load becomes the key for the operators, the evaluation index of the protection effect is obtained through the titanium balance (Fig. 7).

The fettling rate is defined as the evaluation index of the protection effect:

$$
\begin{gathered}
m_{r-\mathrm{TiO}_{2}}=m_{i-\mathrm{TiO}_{2}}-m_{\mathrm{O}-\mathrm{TiO}_{2}} \\
\Psi=\frac{m_{r-\mathrm{TiO}_{2}}}{m_{i-\mathrm{TiO}_{2}}} \times 100 \%
\end{gathered}
$$

where $m_{r-\mathrm{TiO}_{2}}$ is the residual mass of titania, $\mathrm{kg} / \mathrm{t} ; m_{i-\mathrm{TiO}_{2}}$ is the input mass of titania, $\mathrm{kg} / \mathrm{t} ; m_{o-T i O_{2}}$ is the output mass of titania, $\mathrm{kg} / \mathrm{t} ; \Psi$ is the fettling rate, $\%$.

The protection effect can be evaluated through the fettling 


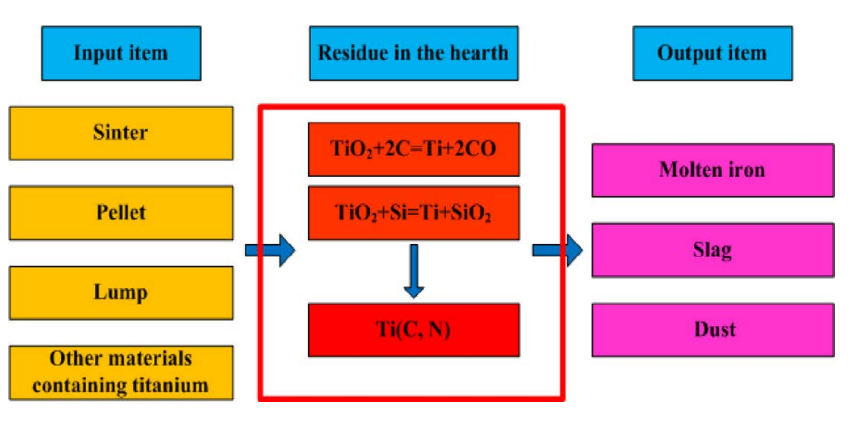

Fig. 7. Schematic diagram of the titanium balance. (Online version in color.)

Table 2. The protection effect evaluation based on the fettling rate.

\begin{tabular}{cc}
\hline The fettling rate & The protection effect \\
\hline$\Psi>>0$ & The carbon brick will be patched quickly \\
$\Psi>0$ & The carbon brick will be patched slowly \\
$\Psi \approx 0$ & The carbon brick will maintain the status \\
$\Psi<0$ & The carbon brick will be eroded slowly \\
$\Psi<<0$ & The carbon brick will be eroded quickly \\
\hline
\end{tabular}

Table 3. The raw materials of a large BF.

\begin{tabular}{cccccccccc}
\hline $\begin{array}{c}\text { Raw } \\
\text { materials }\end{array}$ & $\mathrm{TFe}$ & $\mathrm{SiO}_{2}$ & $\mathrm{Al}_{2} \mathrm{O}_{3}$ & $\mathrm{CaO}$ & $\mathrm{MgO}$ & $\mathrm{S}$ & $\mathrm{TiO}_{2}$ & $\begin{array}{c}\mathrm{TFe}+ \\
\mathrm{TiO}_{2}\end{array}$ \\
\hline Sinter & 57.40 & 5.07 & 1.89 & 10.22 & 1.41 & 0.02 & 0.18 & 57.58 \\
Pellet & 65.47 & 3.24 & 0.61 & 0.69 & 1.59 & 0.01 & 0.08 & 65.55 \\
$\begin{array}{c}\text { Lump } \\
\text { mupted }\end{array}$ & 61.95 & 3.24 & 1.81 & 0.07 & 0.00 & 0.01 & 0.08 & 62.03 \\
$\begin{array}{c}\text { itanium ore } \\
\text { titanium }\end{array}$ & 43.44 & 9.71 & 5.01 & 2.33 & 4.72 & 0.33 & 18.60 & 62.04 \\
$\begin{array}{c}\text { Titanium ore } \\
\begin{array}{c}\text { Chengde } \\
\text { titanium pellet }\end{array}\end{array}$ & 48.00 & 6.93 & 5.71 & 1.37 & 2.80 & 0.32 & 12.00 & 60.00 \\
\hline
\end{tabular}

rate as summarized in Table 2: the carbon brick will be patched when the fettling rate is positive, the carbon brick will maintain the status when the fettling rate is approximately equal to zero. However, the carbon brick will be eroded when the fettling rate is negative, it is necessary to adjust the operation to increase the titanium load. In summary, the reasonable operation during protection can be obtained according to the fettling rate.

\subsection{The Application of the Model}

The raw materials of a large BF are presented in Table 3. The sinter, the pellet and the lump are the basic materials, while the imported titanium ore, the titanium ore and the Chengde titanium pellet are the raw materials for protection. The model can be used to compare the economy of the raw materials for protection.

The lower limit of the effective titanium content in molten iron, the maximum titanium distribution ratio, the titania content in slag and the economic titanium load are shown in Table 4. The basic materials remains unchanged: sinter+pellet+lump + raw materials for protection, calculate the cost of raw materials for protection. The cost of raw material for protection, cost of flux consumption, saving the cost of molten iron and cost of coke consumption are listed
Table 4. The economic titanium load.

\begin{tabular}{ccccc}
\hline Item & $\begin{array}{c}\text { The lower } \\
\text { limit }[\mathrm{Ti}], \%\end{array}$ & $\begin{array}{c}\text { The maximum } \\
{[\mathrm{Ti}] /\left(\mathrm{TiO}_{2}\right)}\end{array}$ & $\begin{array}{c}\left(\mathrm{TiO}_{2}\right), \\
\%\end{array}$ & $\begin{array}{c}\text { The economic } \\
\text { titanium load, } \mathrm{kg} / \mathrm{t}\end{array}$ \\
\hline value & 0.10 & 0.05 & 2 & 7.41 \\
\hline
\end{tabular}

Table 5. The cost of raw material for protection.

\begin{tabular}{cccc}
\hline Raw materials for protection & Mass, $\mathrm{kg} / \mathrm{t}$ & Price, $\mathrm{RMB} / \mathrm{kg}$ & $\mathrm{P}_{1}, \mathrm{RMB} / \mathrm{t}$ \\
\hline Chengde titanium pellet & 39 & 555 & 21.65 \\
Imported titanium ore & 28 & 673 & 18.84 \\
Titanium ore & 43 & 656 & 28.21 \\
\hline
\end{tabular}

Table 6. The cost of flux consumption.

\begin{tabular}{cccc}
\hline Raw materials for protection & Mass, $\mathrm{kg} / \mathrm{t}$ & Price, $\mathrm{RMB} / \mathrm{kg}$ & $\mathrm{P}_{2}, \mathrm{RMB} / \mathrm{t}$ \\
\hline Chengde titanium pellet & 2.18 & 277 & 0.60 \\
Imported titanium ore & 2.47 & 277 & 0.69 \\
Titanium ore & 2.84 & 277 & 0.79 \\
\hline
\end{tabular}

Table 7. Saving the cost of molten iron.

\begin{tabular}{cccc}
\hline Raw materials for protection & Mass, $\mathrm{kg}$ & Price, $\mathrm{RMB} / \mathrm{kg}$ & $\mathrm{P}_{3}, \mathrm{RMB} / \mathrm{t}$ \\
\hline Chengde titanium pellet & 22.10 & 1923 & -42.50 \\
Imported titanium ore & 13.03 & 1923 & -25.06 \\
Titanium ore & 22.56 & 1923 & -43.38 \\
\hline
\end{tabular}

Table 8. The cost of coke consumption.

\begin{tabular}{crccc}
\hline Raw materials for protection heat, $\mathrm{kJ}$ & $\begin{array}{c}\text { Coke mass, } \\
\mathrm{kg} / \mathrm{t}\end{array}$ & $\begin{array}{c}\text { Price, } \\
\mathrm{RMB} / \mathrm{kg}\end{array}$ & $\begin{array}{c}\mathrm{P}_{4}, \\
\mathrm{RMB} / \mathrm{t}\end{array}$ \\
\hline Chengde titanium pellet & 831.16 & 29.63 & 1717 & 50.88 \\
Imported titanium ore & 1234.06 & 44.00 & 1717 & 75.54 \\
Titanium ore & 1568.83 & 55.93 & 1717 & 96.03 \\
\hline
\end{tabular}

Table 9. The total cost.

\begin{tabular}{ccc}
\hline Raw materials for protection & Mass, $\mathrm{kg} / \mathrm{t}$ & $\mathrm{P}, \mathrm{RMB} / \mathrm{t}$ \\
\hline Chengde titanium pellet & 39 & 30.63 \\
Imported titanium ore & 28 & 70.01 \\
Titanium ore & 43 & 81.65 \\
\hline
\end{tabular}

in Tables 5, 6, 7 and $\mathbf{8}$, respectively. The total cost is summarized in Table 9, the economic order of raw materials for protection: Chengde titanium pellet $>$ the imported titanium ore $>$ the titanium ore.

The relationship between the fettling rate and the thermocouple temperature of a commercial BF is shown in Fig. 8. It can be concluded from Fig. 8, the protection effect was reflected by the fettling rate. The temperature increased rapidly when the fettling rate reduced, especially when the fettling rate was negative, the temperature reached the highest. While, the temperature decreased when the fettling rate remained above $30 \%$.

\section{Conclusions}

In order to clarify the erosion mechanism of carbon brick 


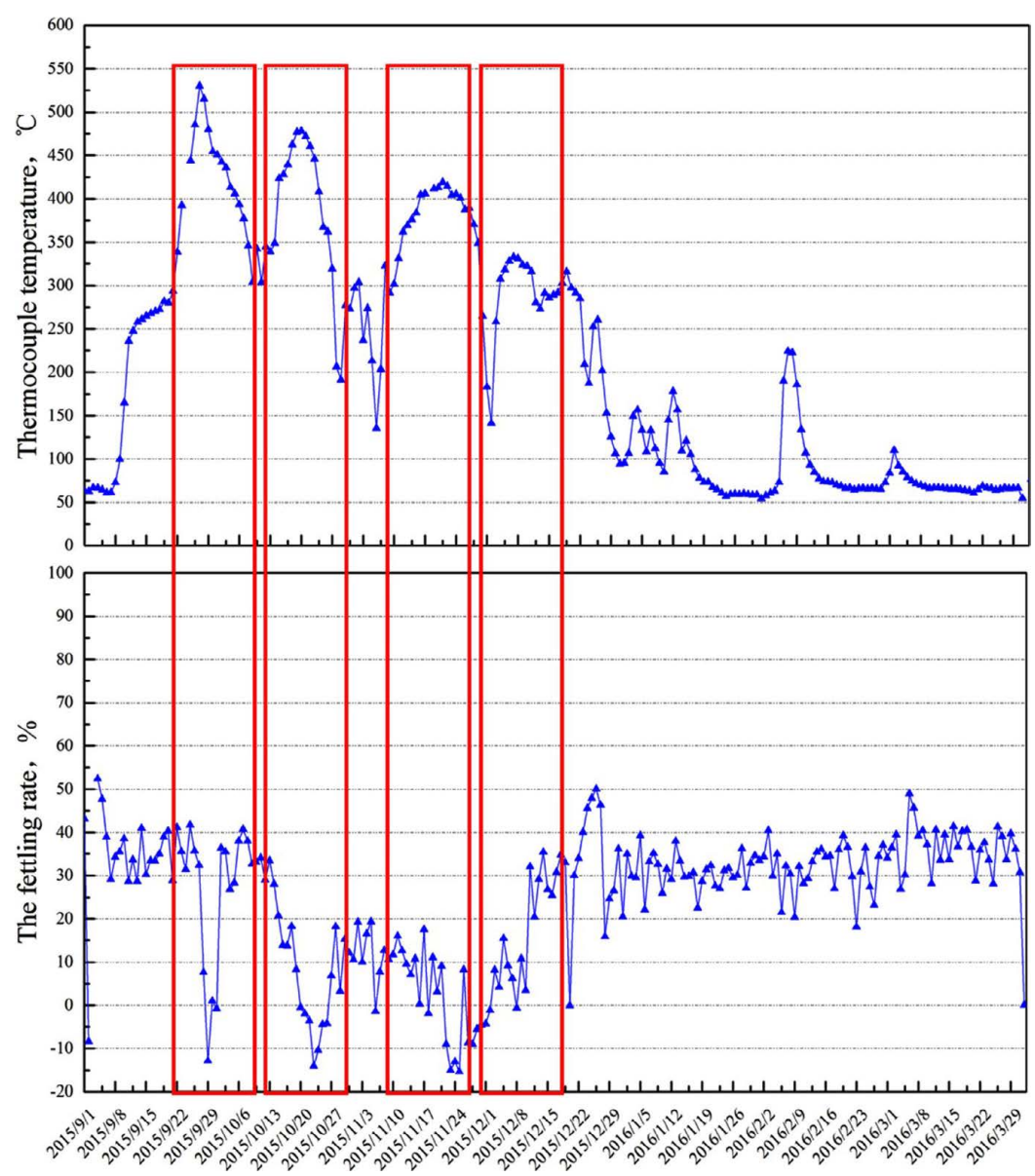

Fig. 8. The relationship between the fettling rate and the thermocouple temperature. (Online version in color.)

and realize the economical and efficient protection for blast furnace hearth at the end of the service, the damaged carbon bricks were analyzed, a model of economical and efficient protection for hearth was established, the fallowing results were summarized:

(1) The carbon content of molten iron is undersaturated in hearth, the carbon undersaturation degree is related to the volume of $\mathrm{BF}$, the carbon undersaturation degree of large $\mathrm{BF}$ is lower which may be the reason of long service life for large BF.

(2) The dissolution and the penetration were considered as the reasons for the erosion of carbon brick. The erosion of carbon brick can be divided into four processes, the four processes constitute a cycle which causes the erosion of carbon brick gradually.

(3) The economic evaluation was established based on the titanium content of molten iron, the distribution ratio of titanium, the composition of raw material, the price of raw material and the operation of $\mathrm{BF}$, the model guides the selection of the economical protection raw material according to the evaluation.

(4) The fettling rate was defined as the evaluation index of the protection effect, the protection effect can be reflected by the fettling rate.

\section{Acknowledgments}

This work was financially supported by the National Science Foundation for Young Scientists of China (51704019), Major Science and Technology Program for Water Pollution Control and Treatment (2017ZX07402001), sup- ported by the Fundamental Research Funds for the Central Universities(FRF-BD-17-010A) and (FRF-TP-17-040A1).

\section{REFERENCES}

1) Z. J. Liu, J. L. Zhang and T. J. Yang: ISIJ Int., 55 (2015), 1146.

2) K. X. Jiao, J. L. Zhang, Z. J. Liu, C. L. Chen and Y. X. Liu: ISIJ Int., 56 (2016), 1956.

3) Y. Deng, J. L. Zhang and K. X. Jiao: Metall. Res. Technol., 114 (2017), 1.

4) Y. Hino, H. Matsunaga and K. Watanabe: ISIJ Int., 57 (2017), 697.

5) Z. J. Liu, J. L. Zhang, T. J. Yang and H. B. Zuo: ISIJ Int., 52 (2012), 1713.

6) C. L. Yeh and Y. D. Chen: Ceram. Int., 31 (2005), 719.

7) Y. J. Park, S. W. Kim and S. Kang: Mater. Sci. Eng. A, 291 (2000), 198.

8) Y. Morizane, B. Ozturk and R. Fruehan: Metall. Mater. Trans. B, 30 (1999), 29.

9) Y. Li and R. Fruehan: Metall. Mater. Trans. B, 32 (2001), 1203.

10) J. Li, Z. Zhang, L. Liu, W. Wang and X. Wang: ISIJ Int., 53 (2013), 1696.

11) J. L. Liao, J. Li, X. D. Wang and Z. T. Zang: Ironmaking Steelmaking, 39 (2012), 133.

12) S. J. Nam, Y. B. Kang, S. M. Jung and Y. Sasaki: ISIJ Int., 53 (2013), 1779.

13) T. Ohno, K. Sarukawa, K. Tokieda and M. Matsumura: J. Catal., 203 (2001), 82.

14) D. Chu, G. Qin, X. Yuan, M. Xu, J. Lu and P. Zheng: J. Porous Mater., 15 (2008), 661.

15) Y. Jin, Y. B. Zong, H. Bai and D. Q. Cang: Int. Conf. on Science \& Technology of Ironmaking, Vol. 16, Journal of Iron and Steel Research, Beijing, (2009), 902.

16) J. Z. Zhang, L. Wen, M. H. Long and B. N. Yang: Key Eng. Mater., 467 (2011), 1742.

17) Y. Chen, E. Ishizuka, N. Yoshikawa and S. Taniguchi: ISIJ Int., 47 (2007), 193.

18) F. Mccarthy, R. Khanna, V. Sahajwalla and N. Simento: ISIJ Int., 45 (2005), 1261.

19) M. Rahman, R. Khanna, V. Sahajwalla and P. Okane: ISIJ Int., 49 (2009), 329.

20) X. L. Wang: Ferrous Metallurgy (Ironmaking part), Metallurgical Industry Press, Beijing, (2014), 164. 